\title{
Do the soil particle size influence ecosystem development on postindustrial sites?
}

\author{
Agnieszka BŁOŃSKA ${ }^{1}$ - Edyta SIERKA ${ }^{1}$ - Łukasz RADOSZ ${ }^{1}$ - Franco MAGURNO ${ }^{1,2}$ - \\ Gabriela WOŹNIAK ${ }^{1}$ \\ 1: Department of Botany and Nature Protection; Faculty of Biology and Environmental Protection, University of \\ Silesia in Katowice, Jagiellońska 28, 40-032 Katowice, Poland; E-mail: gabriela.wozniak@us.edu.pl \\ 2: Centre of Mountain Environmental Technologis, Hołcyna 219, 43-438 Brenna, Poland
}

Keywords: initial soil properties, soil particle size, vegetation development, primary succession

\section{Introduction}

The relationship between the spontaneously developing of biota (including vegetation) and soil (or soil substratum), physicochemical (particle size fraction) properties and the functions on postindustrial sites is low (Kompała-Bąba et al. 2019). For soil quality and the soil function recovery (e.g. regulation of water infiltration, nutrient availability) particle size fraction participation is an important factor (Christensen 2001, Hemkemeyer et al. 2018). The fine particle fraction is known as playing an important role in the regulation of soil nutrients and soil water content (Hemkemeyer et al. 2018). The coal spoil heaps studied here are located in an urban-industrial landscape and each have different mosaic of habitat conditions and thus form a kind of environmental islands. The relations between soil substrate particle size fraction and the soil substratum properties as well as biotic postindustrial soil substratum (including spontaneous vegetation) on coal mine heaps have been studied. The aim of the study was to determine: (1) how do soil particle size fraction properties vary in relation to different biotic (arbuscular mycorrhizal fungi AMF, bacteria, vegetation diversity); (2) what are the relations between the granulometric composition of the soil substrate and the biotic soil substratum parameters.

\section{Materials and methods}

In each plot the vegetation species composition and abundance have been recorded and the associated soil samples have been collected. For each research plots the prevailing particle size fraction was determined (stones, gravel, sand, silt). AMF colonization level, bacteria (Biolog, PLFA), vegetation diversity parameters have been determined. For the recorded vegetation patches the species richness, Shannon-Wiener diversity index, Simpson and Evenness indicators were used to determine species diversity. Additionally such functional traits were selected as: life forms, life strategies and ecological groups.

\section{Results and discussion}

It has been shown that the highest species diversity and the highest values of ShannonWiener diversity index, as well as Simpson and Evenness indicators were obtained for plots recorded on a coarse substrate. Moreover the greatest variation due to the participation of vascular plant species representing different habitats, life forms, and life strategies have been found on a gravel site. The distribution of the number of patches depending on the granulometric structure of the substrate and the life strategy represented by the dominant species in a given patch is shown in Table 1. 
Table 1. Distribution of number of patches in relation to the coarseness of the substrate and life strategy of the dominant species in the patch $(G=225,335 ; p<0,001)$.

\begin{tabular}{lccccc}
\hline & \multicolumn{5}{c}{ number of patches } \\
\cline { 2 - 6 } Life strategy & Dust & Sand & Grave & Stones & Total \\
\hline competitors & 18 & 222 & $\mathbf{6 8 0}$ & 76 & 996 \\
stress-tolerant & 2 & 34 & $\mathbf{5 5}$ & 17 & 108 \\
ruderals & 10 & 55 & 51 & 4 & 120 \\
competitive-ruderal & 10 & 132 & $\mathbf{3 4 0}$ & 38 & 520 \\
stress-tolerant ruderal & 11 & 33 & $\mathbf{4 3}$ & 4 & 91 \\
C-S-R strategist & 72 & 152 & $\mathbf{3 3 3}$ & 31 & 588 \\
stress-tolerant competitor & 37 & 34 & $\mathbf{7 0}$ & 3 & 144 \\
\hline total & 160 & 662 & 1572 & 173 & 2567 \\
\hline
\end{tabular}

Vegetation patches present on substrates with different granulometric compositions of the post industrial sites soil substrate, are dominated by species representing the whole spectrum of different life strategies. The largest number of vegetation patches was found on the substrate in which the gravel fraction dominated. The vegetation in which the species with the R (ruderal) strategy dominate, develop frequently on the soil substrate with the sand and gravel structure. On the gravel prevailed soil substrate the patches dominated by species with the C, CS strategy are most frequent.

\section{Conclusions}

We found that the prevailing particle size fraction in the soil substrate of the coal mine heaps influenced the diversity of the developing vegetation on these post-industrial sites. The fine particle sizes, along with Rother physicochemical parameters such as some exchangeable cations, soil moisture, available $\mathrm{Mg}$, electrical conductivity, $\mathrm{pH}$ and total carbon made the most significant contribution to the variation in the diversity of the vegetation developing spontaneously on coal mine heaps.

\section{Acknowledgement}

The study was part of the InfoRevita project TANGO ID:268600 financed by NCBiR

\section{References}

Christensen, B.T. (2001): Physical fractionation of soil and structural and functional complexity in organic matter turnover. Eur J Soil Sci. 52: 345-353. DOI: https://doi.org/10.1046/j.1365-2389.2001.00417.x

Hemkemeyer, M., Dohrmann, A.B., Christensen, B.T., Tebbe, C.C. (2018): Bacterial Preferences for Specific Soil Particle Size Fractions Revealed by Community Analyses. Front Microbiol. 9: 149. DOI: https://doi. org/10.3389/fmicb.2018.00149

Kompała-Bąba A., Bierza W., Błońska A., Sierka E., Magurno F., Chmura D., Besenyei L., Radosz Ł., Woźniak G. (2019): Vegetation diversity on coal mine spoil heaps - how important is the texture of the soil substrate? Biologia (in press). 